\title{
The Role of Sentinel Lymph Node Biopsy in Patients with Merkel Cell Carcinoma: Uncertainty Prevails
}

\author{
John F. Thompson, $\mathrm{MD}^{1,3,5}$ and George Hruby, $\mathrm{MBChB}^{2,4}$ \\ ${ }^{1}$ Department of Melanoma and Surgical Oncology, Royal Prince Alfred Hospital, Camperdown, NSW, Australia; \\ ${ }^{2}$ Department of Radiation Oncology, Lifehouse, Camperdown, NSW, Australia; ${ }^{3}$ Discipline of Surgery, The University of \\ Sydney, Sydney, NSW, Australia; ${ }^{4}$ Discipline of Medicine, The University of Sydney, Sydney, NSW, Australia; \\ ${ }^{5}$ Melanoma Institute Australia, North Sydney, NSW, Australia
}

\begin{abstract}
"Uncertainty is an uncomfortable position. Certainty is an absurd one."-Voltaire

Sentinel lymph node (SLN) biopsy is a minimally invasive staging procedure that is now used in a wide range of cancer types to allow rational planning of further management. In patients with melanoma and breast cancer, the value of SLN biopsy is firmly established. It also provides useful and apparently reliable staging information for patients with other forms of cancer in which lymphatic spread to regional lymph nodes occurs. These include squamous cell carcinoma of the skin, oro-pharyngeal cancer, clear cell sarcoma, penile cancer, vulvar cancer, cervical cancer, vaginal cancer, endometrial cancer, testicular cancer, prostate cancer, esophageal cancer, gastric cancer, colorectal cancer, anal cancer, thyroid cancer, extra mammary Paget's disease, and lung cancer. The value of SLN biopsy in patients with Merkel cell carcinoma (MCC), however, has not been clearly established, and its role in managing these patients remains unclear.

The study by Kachare et al. ${ }^{1}$ reported in this issue of Annals of Surgical Oncology sheds some light on the matter, and its results suggest that management based on SLN status improves survival in patients with MCC. It was a large and well-conducted study, but the SEER data on
\end{abstract}

This comment refers to the article available at doi:10.1245/s10434013-3434-3.

\section{(C) Society of Surgical Oncology 2014}

First Received: 6 February 2014;

Published Online: 7 March 2014

J. F. Thompson, MD

e-mail: john.thompson@melanoma.org.au which it was based were collected retrospectively, with possible biases at play, and the findings therefore should be regarded as hypothesis-generating rather than definitive. Biases may have been introduced for several reasons. Was SLN biopsy more likely to have been performed in younger, fitter patients and in those more likely to have T1 tumors managed at centers of excellence? What other investigations and treatments apart from radiation therapy (RT) might the patients have received? (And it must be noted that specific RT details are not available from the SEER database, e.g., whether it was administered to the primary tumor site, the regional lymph nodes, or both.) Could the fact that RT was more frequently given to patients who had a SLN biopsy than to those who did not (58 vs. $40 \%$ ) have been responsible, partly or wholly, for the better outcome in the SLN biopsy group? (This factor does not appear to have been included in the multivariate analysis that was performed.) Was SLN biopsy more likely to have been performed in recently treated patients compared with those treated earlier in the series? There may also have been selection bias, because although 3,118 patients with MCC were identified in the SEER database, more than half of them were excluded.

The results of two other studies are pertinent to this discussion. For patients treated at the Memorial SloanKettering Cancer Center, Fields et al. ${ }^{2}$ reported that SLN status predicted neither recurrence nor survival. The 153 patients in this study make it the largest single-center experience of SLN biopsy in MCC reported to date. More recently, Fritsch et al. from the Medical University of South Carolina interrogated the SEER database from 1998 to 2008 to assess the role of SLN biopsy in head and neck MCC. $^{3}$ Of 721 patients with MCC who underwent SLN biopsy, $173(24 \%)$ had head and neck primaries. The rate 
of SLN positivity was not significantly different for head and neck and non-head and neck MCC (23 vs. $27 \%$, $p=0.36$ ). The authors concluded that SLN status was not an independent predictor of survival in head and neck MCC. Unlike the MSKCC group, they could not comment on disease-free survival, because the SEER database does not record patterns and rates of recurrence.

\section{IS SLN BIOPSY RELIABLE IN PATIENTS WITH MERKEL CELL CARCINOMA?}

Several studies have suggested that SLN biopsy does not predict outcome in patients with MCC with the same degree of reliability as it does in other cancers. For example, our experience in Sydney, albeit in a small number of patients, has been that there was an unacceptably high failure rate for SLN biopsy in this disease (recurrence occurred in 5 of 8 patients who were SLNnegative). ${ }^{4}$ This was despite formidable experience with the technique in the setting of melanoma by the operating surgeons, pathologists, and nuclear medicine physicians at our institution. A more recent series, from another center in Sydney, likewise reported a high recurrence rate in SLNnegative patients with MCC ( 2 of 8$).{ }^{5}$ Centers in other parts of the world also have reported high failure rates after a negative SLN biopsy (ranging from 5-33\%). ${ }^{6-8}$

\section{IS SLN BIOPSY USEFUL IN MERKEL CELL CARCINOMA?}

As opposed to melanoma or breast cancer, MCC is extremely radio-sensitive, and an alternative treatment paradigm to surgical management of the primary tumor by wide local excision is definitive RT or chemoradiation (CRT). This approach is expedient, especially in those who have had a biopsy only or an incomplete excision, because it avoids the delay in commencing RT (as well as avoiding the morbidity and potential disfigurement of wide local excision). The regional nodes may also be managed simultaneously with RT or C-RT in an elective or definitive fashion. A series of prospective trials conducted by TROG (the Trans Tasman Radiation Oncology Group) has examined the role of definitive C-RT in high-risk MCC. High risk was defined as a primary tumor greater than $1 \mathrm{~cm}$ in diameter, involved nodes, recurrent disease following surgery alone, or gross residual disease. None of these prospective trials mandated SLN biopsy or even complete excision, and they have relied on C-RT to treat both the primary site (definitive or adjuvant) and the draining node field (elective or definitive). ${ }^{9-11}$ Furthermore, two retrospective series from Australia and one from the United States used definitive RT or C-RT with consistently excellent outcomes. ${ }^{12-14}$ Thus, when employing a nonsurgical paradigm to treat this disease, SLN biopsy may be unnecessary, at least for high-risk disease.

\section{ARE THERE OTHER WAYS OF STAGING PATIENTS WITH MERKEL CELL CARCINOMA?}

Retrospective data from Melbourne suggest that FDGPET will alter the staging of patients with MCC in $22 \%$ of cases and change management in $37 \%{ }^{15}$ Thus, it seems likely that FDG-PET will prove useful in staging this disease, particularly in patients with larger primary tumors and/or who are node-positive. Patients are currently accruing to the TROG 0903 (MP-3) trial, which prospectively evaluates the role of FDG-PET in MCC larger than $2 \mathrm{~cm}$ and/or clinically node positive and/or when disease is locally recurrent managed by definitive C-RT (ClinicalTrials.gov Identifier: NCT01013779).

\section{CONCLUSIONS}

Merkel cell carcinoma remains an enigmatic disease entity that does not behave like other skin malignancies. With limited information from prospective studies to guide us, the optimal staging and management strategies for MCC have not yet been clearly defined. The discomfort of uncertainty remains, and Voltaire may rest easy. Nevertheless, our understanding of MCC is improving, little by little, and more effective management strategies are slowly emerging from the disconcerting fog of that uncertainty. As far as SLN biopsy in patients with MCC is concerned, welldesigned, prospective studies are clearly required to clarify its role.

\section{REFERENCES}

1. Kachare SD, Wong JH, Vohra NA, et al. Sentinel lymph node biopsy is associated with improved survival in Merkel cell carcinoma. Ann Surg Oncol. 2013; doi:10.1245/s10434-013-3434-3.

2. Fields RC, Busam KJ, Chou JF, et al. Recurrence and survival in patients undergoing sentinel lymph node biopsy for merkel cell carcinoma: analysis of 153 patients from a single institution. Ann Surg Oncol. 2011;18:2529-37.

3. Fritsch VA, Camp ER, Lentsch EJ. Sentinel lymph node status in Merkel cell carcinoma of the head and neck: not a predictor of survival. Head Neck. 2014; doi:10.1002/hed.23334.

4. Warner RE, Quinn MJ, Hruby G, et al. Management of merkel cell carcinoma: the roles of lymphoscintigraphy, sentinel lymph node biopsy and adjuvant radiotherapy. Ann Surg Oncol. 2008;15:2509-18.

5. Howle J, Veness M. Sentinel lymph node biopsy in patients with Merkel cell carcinoma: an emerging role and the Westmead hospital experience. Australas J Dermatol. 2012;53:26-31.

6. Maza S, Trefzer U, Hofmann M, et al. Impact of sentinel lymph node biopsy in patients with Merkel cell carcinoma: results of a prospective study and review of the literature. Eur J Nucl Med Mol Imaging. 2006;33:433-40. 
7. Pan D, Narayan D, Ariyan S. Merkel cell carcinoma: five case reports using sentinel lymph node biopsy and a review of 110 new cases. Plast Reconstr Surg. 2002;110:1259-65.

8. Rodrigues LK, Leong SP, Kashani-Sabet M, et al. Early experience with sentinel lymph node mapping for Merkel cell carcinoma. J Am Acad Dermatol. 2001;45:303-8.

9. Poulsen M, Rischin D, Walpole E, et al. High-risk Merkel cell carcinoma of the skin treated with synchronous carboplatin/etoposide and radiation: a Trans-Tasman Radiation Oncology Group Study-TROG 96:07. J Clin Oncol. 2003;21:4371-6.

10. Poulsen M, Walpole E, Harvey J, et al. Weekly carboplatin reduces toxicity during synchronous chemoradiotherapy for Merkel cell carcinoma of skin. Int J Radiat Oncol Biol Phys. 2008;72:1070-4.

11. Finnigan R, Hruby G, Wratten C, et al. The impact of preradiation residual disease volume on time to locoregional failure in cutaneous Merkel cell carcinoma-a TROG substudy. Int J Radiat Oncol Biol Phys. 2013;86:91-5.

12. Sundaresan P, Hruby G, Hamilton A, et al. Definitive radiotherapy or chemoradiotherapy in the treatment of Merkel cell carcinoma. Clin Oncol (R Coll Radiol). 2012;24:e131-6.

13. Veness M, Foote M, Gebski V, et al. The role of radiotherapy alone in patients with merkel cell carcinoma: reporting the Australian experience of 43 patients. Int J Radiat Oncol Biol Phys. 2010;78:703-9.

14. Fang LC, Lemos B, Douglas J, et al. Radiation monotherapy as regional treatment for lymph node-positive Merkel cell carcinoma. Cancer. 2010;116:1783-90.

15. Siva S, Byrne K, Seel M, et al. 18F-FDG PET provides highimpact and powerful prognostic stratification in the staging of Merkel cell carcinoma: a 15 year institutional experience. $J$ Nucl Med. 2013;54:1223-9. 